\title{
Analisis Tinggi Muka Air Laut Menggunakan Receiver Multi-Frekuensi dan Multi-GNSS di Perairan Sulawesi
}

Sea Water Level Analysis Using Multi-Frequency and Multi-GNSS Receiver in Sulawesi Waters

\author{
Markus Juliano Sinaga ${ }^{1}$, Mokhamad Nur Cahyadi*2, Danar Guruh Pratomo ${ }^{3}$, Nobuhiro Kishimoto ${ }^{4}$, \\ Dwi Hariyanto 5 \\ 1,2,3 Departemen Teknik Geomatika, FTSLK-ITS, Kampus ITS Sukolilo, Surabaya, 60111, Indonesia \\ ${ }^{4}$ Magellan Systems Japan, Amagasaki Research Incubation Center, Doicho, Amagasaki, Hyogo, Jepang \\ ${ }^{5}$ Balai Teknologi Survei Kelautan-BPPT, Jl. M.H. Thamrin 8, Jakarta, 10340, Indonesia \\ *Korespondensi penulis: cahyadi@geodesy.its.ac.id
}

Diterima: 14082020; Diperbaiki: 24082020; Disetujui: 03092020; Dipublikasi: 21012021

\begin{abstract}
Abstrak: Pasang surut air laut merupakan variasi vertikal muka air laut. Pasang surut air laut merupakan salah satu komponen penting dalam survei batimetri. Pada survei batimetri secara umum, pengamatan pasang surut air laut dilakukan dengan menggunakan rambu pasut di lokasi survei batimteri. Seiring berkembangnya teknologi, penggunaan Global Navigation Satellite System (GNSS) semakin memungkinkan dalam survei batimetri. Selain dalam penentuan posisi horisontal, GNSS juga dapat digunakan untuk menentukan posisi vertikal. Salah satu sistem GNSS yang akurat saat ini adalah Quasi-Zenith Satellite System (QZSS) milik Jepang. Sistem ini memiliki satelit yang selalu mengorbit di sebagian wilayah Indonesia sehingga akan memberikan layanan pemosisian satelit yang sangat akurat. Pada penelitian ini, data pengamatan diperoleh dari receiver multi-frekuensi dan multi-GNSS. Receiver tersebut dapat menerima sinyal dari sistem QZSS. Data pengamatan tersebut kemudian dibandingkan dengan model prediksi pasang surut milik Badan Informasi Geospasial (BIG). Selanjutnya, dilakukan analisis untuk melihat tingkat kesalahan pola yang dihasilkan dari kedua data tersebut. Uji tingkat kesalahan dilakukan dengan perhitungan Root Mean Square Error (RMSE). Hasil penelitian ini menunjukkan bahwa nilai RMSE maksimum dan minimum pada perbandingan pengamatan pasut QZSS dan prediksi pasut BIG masing-masing sebesar 2,317 m dan 0,176 m dari total 11 hari pengamatan. RMSE maksimum terjadi pada 10 Agustus 2019 dan minimum pada 9 Agustus 2019. Selain pada tanggal 9 Agustus 2019, hasil yang baik juga diperoleh pada tanggal 8, 12, 14, 15, dan 16 Agustus 2019 dengan nilai RMSE kurang dari setengah meter.
\end{abstract}

Copyright $@ 2020$ Geoid

\begin{abstract}
Tide is a vertical variation of sea level. The tide of seawater is an essential component of a bathymetric survey. In general, tide observations are carried out by using tide poles at the survey site for bathymetry. As technology has developed, the use of the Global Navigation Satellite System (GNSS) has become increasingly possible in bathymetric surveys. Apart from determining the horizontal position, GNSS can also be used to determine the vertical position. One of the most accurate GNSS systems today is Japan's Quasi-Zenith Satellite System (QZSS). This system has satellites that are always orbiting in parts of Indonesia so that it will provide highly accurate satellite positioning services. In this study, observational data were obtained from multi-frequency and multi-GNSS receivers. The receiver can receive signals from the QZSS system. The observational data are then compared with the Geospatial Information Agency (BIG)'s tidal prediction model. Furthermore, an analysis was carried out to see the pattern error rate resulting from the two data. Error level test is done by calculating Root Mean Square Error(RMSE). This study's results indicate that the maximum and minimum RMSE values in the comparison of QZSS tidal observations and BIG tidal predictions are $2.317 \mathrm{~m}$ and $0.176 \mathrm{~m}$, respectively, from a total of 11 observation days. The maximum RMSE occurred on 10 August 2019 and the minimum on 9 August 2019. Apart from 9 August 2019, good results were also obtained on 8, 12, 14, 15, and 16 August 2019 with an RMSE value of less than half a meter.
\end{abstract}

Kata kunci : GNSS; pasang surut; prediksi pasang surut 


\section{Pendahuluan}

Pasang surut air laut atau sering disebut pasut adalah fenomena alam naik-turunnya permukaan air laut secara periodik sebagai akibat dari adanya gaya gravitasi benda-benda langit terutama bulan dan matahari. Pengaruh benda astronomi lainnya dapat diabaikan karena jarak dan ukurannya yang relatif lebih kecil daripada Bulan dan Matahari. Pasut di perairan semi tertutup seperti teluk dipengaruhi oleh faktor nonastronomi yaitu berupa bentuk garis pantai dan topografi dasar perairan (Stewart, 2008).

Pengamatan pasut dilakukan dengan tujuan untuk mengetahui nilai gerakan vertikal permukaan air laut yang terjadi secara periodik. Selanjutnya, data pengamatan pasut tersebut digunakan untuk koreksi kedalaman hasil pemeruman. Namun, terkadang daerah pemeruman dan titik pengamatan pasut tidak berdekatan atau daerah pemeruman berada jauh di lepas pantai, padahal karakteristik pasang surut laut dapat berbeda antar satu daerah dengan daerah lainnya (Haryono dan Narni, 2004). Oleh karena itu, ada kemungkinan data pasut tersebut tidak valid jika digunakan untuk koreksi pemeruman. Salah satu solusi untuk menjawab permasalahan tersebut adalah penggunaan Global Navigation Satellite System (GNSS) untuk pengamatan pasut. GNSS dapat digunakan untuk penentuan posisi dan tinggi dengan ketelitian mencapai milimeter.

Penggunaan GNSS dapat digunakan untuk mengatasi perbedaan karakteristik pasut di tempat yang berbeda. Receiver GNSS dapat digunakan di kapal/perahu bersamaan dengan dilakukannya pemeruman. Dengan adanya akurasi tinggi dari GNSS, bidang elipsoid mulai digunakan untuk mendefinisikan datum vertikal. Data yang didapat dari survei darat dan laut dapat berhubungan dengan bidang referensi vertikal yang sama. Meskipun referensi elipsoid mudah untuk didapatkan, tetapi itu bukanlah permukaan fisik seperti yang didefinisikan dari gravitasi (datum geodetik) atau muka air laut rata-rata (datum pasut). Oleh karena itu, untuk keperluan analisis dan pembuatan peta laut, nilai ketinggian yang diperoleh GNSS harus diterjemahkan terhadap datum geodetik ataupun datum pasut. Konversi nilai tinggi dari elipsoid ke datum geodetik atau pasut biasanya dilakukan menggunakan pemodelan (Dodd dan Griffin, 2010).

Penelitian ini dilakukan dengan tujuan untuk membuktikan bahwa pengamatan pasang surut air laut untuk keperluan survei batimetri dapat dilakukan dengan penggunaan data GNSS di kapal sehingga untuk keperluan praktis seperti koreksi kedalaman tidak memerlukan pengamatan secara langsung menggunakan palem pasut. Untuk dapat membuktikan itu, data dari pengamatan satelit GNSS perlu dibandingkan dengan data pasut pembanding. Data pembanding yang digunakan dalam penelitian ini adalah model pasut yang dikeluarkan oleh Badan Informasi Geospasial (BIG). Kelemahan dari data prediksi pasut BIG adalah memerlukan beberapa titik prediksi, dimana satu titik prediksi akan mewakili pasang surut disekitarnya. Hal itu dilakukan untuk menyesuaikan dengan posisi kapal yang bergerak. Dengan adanya data pembanding tersebut diharapkan dapat mengetahui selisih antara data pasut GNSS dengan prediksi pasut BIG, sehingga dari perbandingan tersebut dapat ditarik kesimpulan terkait hasil pengamatan pasut menggunakan GNSS di kapal.

\section{Data dan Metode}

Penelitian ini mengambil studi kasus di wilayah perairan Sulawesi, mulai dari Pelabuhan Bitung (Sulawesi Utara) menuju area survei di Laut Selawesi dan Selat Makassar serta berakhir di Pelabuhan Makassar (Sulawesi Selatan). Secara geografis jalur dan koordinat pelayaran kapal ditunjukkan pada Gambar 1 dan Tabel 1 .

Data yang digunakan dalam penelitian ini menggunakan data primer dan sekunder. Data primer pada penelitian ini adalah data pengamatan GNSS di atas kapal yang bergerak di Laut Sulawesi sampai Selat Makassar selama 11 hari (6-16 Agustus 2019). Data pengamatan tersebut menggunakan receiver milik Magellan Systems Japan (MSJ). Sementara itu, data sekunder yang digunakan adalah data model geoid global EGM2008 dan data prediksi pasang surut BIG. Data model geoid global digunakan untuk mengoreksi tinggi eliposid sehingga menjadi tinggi orthometrik dan data prediksi pasang surut sebagai data pembanding terhadap pasut pengamatan GNSS. 
Adapun peralatan yang digunakan dalam penelitian ini berupa beberapa perangkat lunak pengolahan. Penelitian ini menggunakan Alltrans EGM2008 Calculator 1.2 untuk pengolahan data model geoid global EGM2008, perangkat lunak pengolah angka untuk membaca data GNSS dan pengolahan data pasang surut, serta perangkat lunak pengolah data spasial untuk overlay dan layouting analisis pengolahan data.

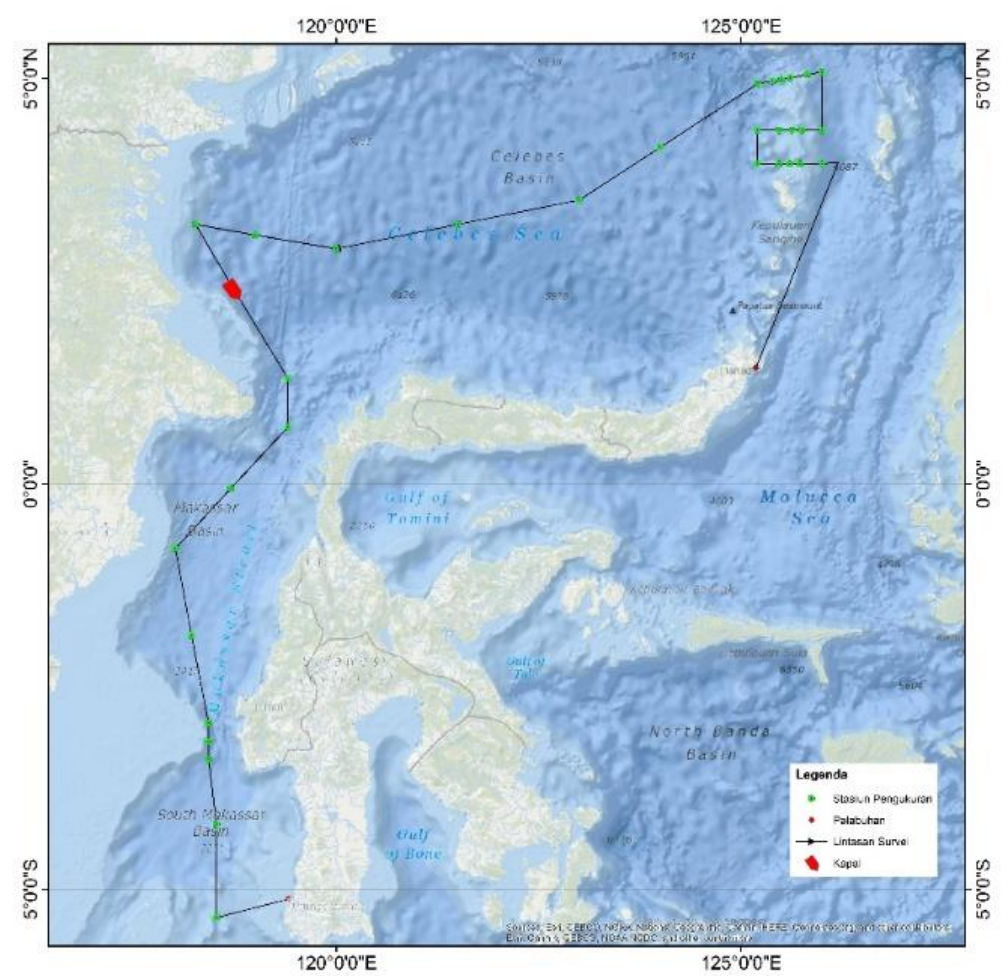

Gambar 1. Lokasi Penelitian (Pengarang, 2020)

Tabel 1. Koordinat Geografis Rencana Pelayaran Kapal (BPPT, 2019)

\begin{tabular}{|c|c|c|c|c|c|}
\hline tasiun & Lokasi & gan & Stasi & Lokasi & \\
\hline St.X1 & $\begin{array}{c}126,00^{\circ} \mathrm{E} \\
3,95^{\circ} \mathrm{N}\end{array}$ & $\begin{array}{c}\text { Pulau } \\
\text { Sangihe }\end{array}$ & St.4 & $\begin{array}{c}123,00^{\circ} \mathrm{E} \\
3,50^{\circ} \mathrm{N}\end{array}$ & $\begin{array}{c}\text { Laut } \\
\text { Sulawesi }\end{array}$ \\
\hline St.X2 & $\begin{array}{c}125,73^{\circ} \mathrm{E} \\
3,95^{\circ} \mathrm{N}\end{array}$ & $\begin{array}{r}\text { Pulc } \\
\text { Sang }\end{array}$ & St.X15 & $\begin{array}{c}121,50^{\circ} \mathrm{E} \\
3,20^{\circ} \mathrm{N}\end{array}$ & $\begin{array}{c}\text { Laut } \\
\text { Sulawesi }\end{array}$ \\
\hline St.1 & $\begin{array}{c}125,60^{\circ} \mathrm{E} \\
3,95^{\circ} \mathrm{N}\end{array}$ & $\begin{array}{c}\text { Pulau } \\
\text { Sangihe }\end{array}$ & St.5 & $\begin{array}{c}120,00^{\circ} \mathrm{E} \\
2,90^{\circ} \mathrm{N}\end{array}$ & $\begin{array}{c}\text { Laut } \\
\text { Sulawesi }\end{array}$ \\
\hline St.X3 & $\begin{array}{r}125,4 \\
3,95\end{array}$ & & St.X16 & $\begin{array}{r}119, \\
3,0\end{array}$ & $\begin{array}{c}\text { Laut } \\
\text { Sulawesi }\end{array}$ \\
\hline St.X4 & $\begin{array}{c}125,20^{\circ} \mathrm{E} \\
3,95^{\circ} \mathrm{N}\end{array}$ & & St.6 & $\begin{array}{c}118,26^{\circ} \mathrm{E} \\
3,20^{\circ} \mathrm{N}\end{array}$ & $\begin{array}{c}\text { Selat } \\
\text { Makassar }\end{array}$ \\
\hline St.X5 & $\begin{array}{r}125,2 \\
4,36 \\
\end{array}$ & & St.X17 & $\begin{array}{r}118, \\
2,4 \\
\end{array}$ & $\begin{array}{c}\text { Selat } \\
\text { Makassar }\end{array}$ \\
\hline St.X6 & $\begin{array}{r}125,4 \\
4,36 \\
\end{array}$ & $\begin{array}{r}\text { Pul } \\
\text { Sans }\end{array}$ & $\mathrm{X} 18$ & $\begin{array}{c}119,40^{\circ} \mathrm{E} \\
1,30^{\circ} \mathrm{N}\end{array}$ & $\begin{array}{c}\text { Selat } \\
\text { Makassar }\end{array}$ \\
\hline St.2 & $\begin{array}{r}125,6 \\
4,36\end{array}$ & $\begin{array}{c}\mathrm{Pu} \\
\mathrm{San}\end{array}$ & St.7 & $\begin{array}{c}119,40^{\circ} \mathrm{E} \\
0,70^{\circ} \mathrm{N}\end{array}$ & $\begin{array}{c}\text { Selat } \\
\text { Makassar }\end{array}$ \\
\hline.$X 7$ & $\begin{array}{c}125,75^{\circ} \mathrm{E} \\
4,36^{\circ} \mathrm{N}\end{array}$ & $\begin{array}{r}\mathrm{Pu} \\
\mathrm{San}\end{array}$ & X19 & $\begin{array}{c}118,70^{\circ} \mathrm{E} \\
0,05^{\circ} \mathrm{S}\end{array}$ & $\begin{array}{c}\text { Selat } \\
\text { Makassar }\end{array}$ \\
\hline St.X8 & $\begin{array}{c}126,00^{\circ} \mathrm{E} \\
4,36^{\circ} \mathrm{N}\end{array}$ & Pulau & St. 8 & $\begin{array}{c}118,01^{\circ} \mathrm{E} \\
0,80^{\circ} \mathrm{S}\end{array}$ & $\begin{array}{c}\text { Selat } \\
\text { Makassar }\end{array}$ \\
\hline St.X9 & $\begin{array}{c}126,00^{\circ} \mathrm{E} \\
5,08^{\circ} \mathrm{N}\end{array}$ & & 20 & $\begin{array}{c}118,21^{\circ} \mathrm{E} \\
1,87^{\circ} \mathrm{S}\end{array}$ & $\begin{array}{c}\text { Selat } \\
\text { Makassar }\end{array}$ \\
\hline 10 & $\begin{array}{c}125,82^{\circ} \mathrm{E} \\
5,05^{\circ} \mathrm{N}\end{array}$ & $\begin{array}{l}\text { Pulau } \\
\text { Sangihe }\end{array}$ & St.X21 & $\begin{array}{c}118,42^{\circ} \mathrm{E} \\
2,95^{\circ} \mathrm{S}\end{array}$ & $\begin{array}{c}\text { Selat } \\
\text { Makassar }\end{array}$ \\
\hline
\end{tabular}




\begin{tabular}{|c|c|c|c|c|c|}
\hline Stasiun & Lokasi & Keterangan & Stasiun & Lokasi & Keterangan \\
\hline St.X11 & $\begin{array}{c}125,61^{\circ} \mathrm{E} \\
5,01^{\circ} \mathrm{N}\end{array}$ & $\begin{array}{c}\text { Pulau } \\
\text { Sangihe }\end{array}$ & St.9 & $\begin{array}{c}118,42^{\circ} \mathrm{E} \\
3,18^{\circ} \mathrm{S}\end{array}$ & $\begin{array}{c}\text { Selat } \\
\text { Makassar }\end{array}$ \\
\hline St.3 & $\begin{array}{c}125,50^{\circ} \mathrm{E} \\
4,99^{\circ} \mathrm{N}\end{array}$ & $\begin{array}{c}\text { Pulau } \\
\text { Sangihe }\end{array}$ & St.X22 & $\begin{array}{c}118,42^{\circ} \mathrm{E} \\
3,40^{\circ} \mathrm{S}\end{array}$ & $\begin{array}{c}\text { Selat } \\
\text { Makassar }\end{array}$ \\
\hline St.X12 & $\begin{array}{c}125,39^{\circ} \mathrm{E} \\
4,97^{\circ} \mathrm{N}\end{array}$ & $\begin{array}{c}\text { Pulau } \\
\text { Sangihe }\end{array}$ & St.X23 & $\begin{array}{c}118,52^{\circ} \mathrm{E} \\
4,20^{\circ} \mathrm{S}\end{array}$ & $\begin{array}{c}\text { Selat } \\
\text { Makassar }\end{array}$ \\
\hline St.X13 & $\begin{array}{c}125,21^{\circ} \mathrm{E} \\
4,94^{\circ} \mathrm{N}\end{array}$ & $\begin{array}{c}\text { Pulau } \\
\text { Sangihe }\end{array}$ & St.10 & $\begin{array}{c}118,52^{\circ} \mathrm{E} \\
5,35^{\circ} \mathrm{S}\end{array}$ & $\begin{array}{c}\text { Selat } \\
\text { Makassar }\end{array}$ \\
\hline St.X14 & $\begin{array}{c}124,00^{\circ} \mathrm{E} \\
4,15^{\circ} \mathrm{N}\end{array}$ & $\begin{array}{c}\text { Laut } \\
\text { Sulawesi }\end{array}$ & & & \\
\hline
\end{tabular}

Pada Gambar 2 menunjukkan diagram alir tahap pengolahan data. Terdapat beberapa data yang akan diolah dalam penelitian ini, yaitu data pasut pengamatan GNSS, data EGM2008, dan data prediksi pasang surut BIG. Pengolahan data yang pertama adalah data pengamatan pasut menggunakan GNSS. Salah satu data output yang dihasilkan dari pengamatan pasut menggunakan GNSS adalah berformat National Marine Electronics Association (NMEA). Di dalam data tersebut berisi banyak informasi-informasi terkait pengamatan GNSS yang dilakukan. Pada penelitian ini, informasi yang digunakan yaitu fix information (GPGGA) dan date and time (GPZDA) sehingga diperlukan ekstraksi karena tidak semua informasi akan digunakan. GPGGA berisi data koordinat geodetik dan GPZDA berisi tanggal dan waktu pengamatan. Ekstraksi pada tahap ini menggunakan perangkat lunak pengolah angka.

Hasil dari ekstraksi data pengamatan GNSS ini adalah koordinat lintang, bujur, dan tinggi elipsoid pada lokasi survei kapal bergerak (rover). Tinggi antena pada rover terhadap permukaan air laut dianggap tetap, meskipun terdapat pengaruh pergerakan kapal (pitch, roll, dan heave).

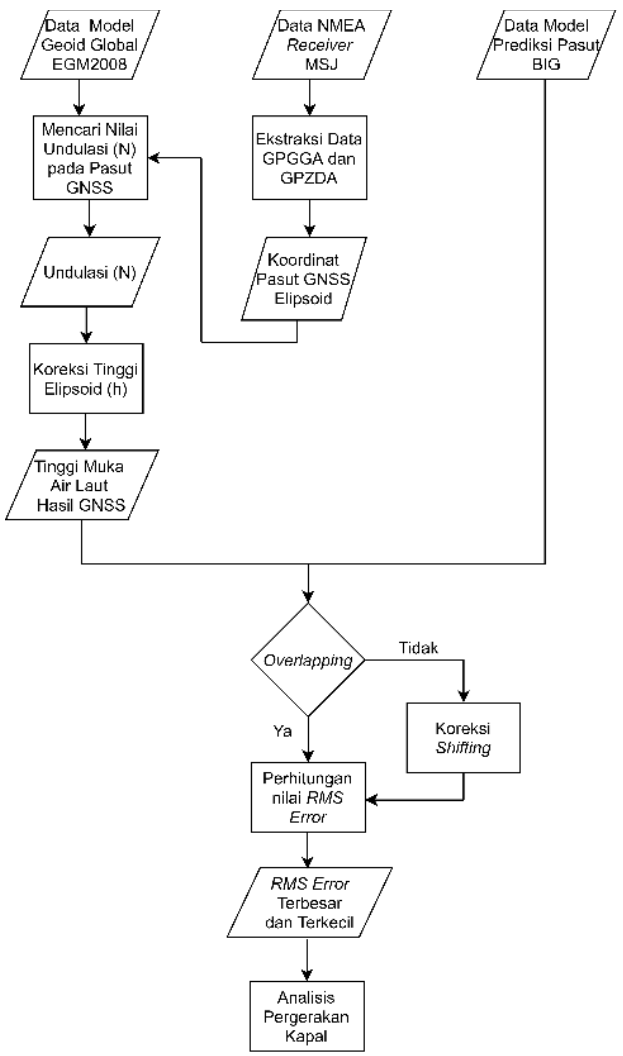

Gambar 2. Diagram Alir

Nilai tinggi muka air laut yang didapatkan masih harus dikoreksi terhadap nilai undulasi di area survei tersebut. Nilai undulasi didapatkan dari pengolahan data model geoid global EGM2008. Data yang diperlukan untuk 
mendapatkan nilai undulasi adalah data perhitungan grid undulasi $1 \times 1$ menit dan program untuk interpolasi data grid $1 \times 1$ menit. Dalam program interpolasi tersebut, diperlukan data input berupa koordinat lintang dan bujur. Data output yang dihasilkan berupa nilai undulasi dari masing-masing kordinat yang dimasukkan.

Nilai undulasi nantinya digunakan untuk mereduksi nilai elipsoid pada koordinat-koordinat pengamatan pasut GNSS agar diperoleh tinggi pasut GNSS yang bereferensi terhadap tinggi geoid yang diasumsikan berhimpit dengan tinggi muka air laut rata-rata atau mean sea level (MSL) (Gambar 3). Persamaannya adalah sebagai berikut (Abidin, 2007):

$$
H_{R(t)}=h_{R(t)}-N_{R(t)}
$$

dimana:

$H_{R(t)} \quad=$ tinggi orthometrik receiver pada saat $\mathrm{t}$,

$h_{R(t)} \quad=$ tinggi elipsoid receiver pada saat $\mathrm{t}$, dan

$N_{R(t)} \quad=$ undulasi di titik receiver pada saat $\mathrm{t}$.

Nilai tinggi muka air laut dapat diperoleh dengan mereduksi nilai tinggi orthometrik receiver dengan tinggi antena receiver terhadap permukaan air laut sehingga persamaannya adalah:

$$
H_{W(t)}=H_{R(t)}-Z_{\text {ant.R }}
$$

dimana:

$H_{W(t)} \quad=$ tinggi orthometrik muka air laut pada saat $\mathrm{t}$,

$H_{R(t)} \quad=$ tinggi orthometrik antena receiver pada saat $\mathrm{t}$, dan

$Z_{\text {ant } R} \quad=$ tinggi antena receiver ke permukaan air laut

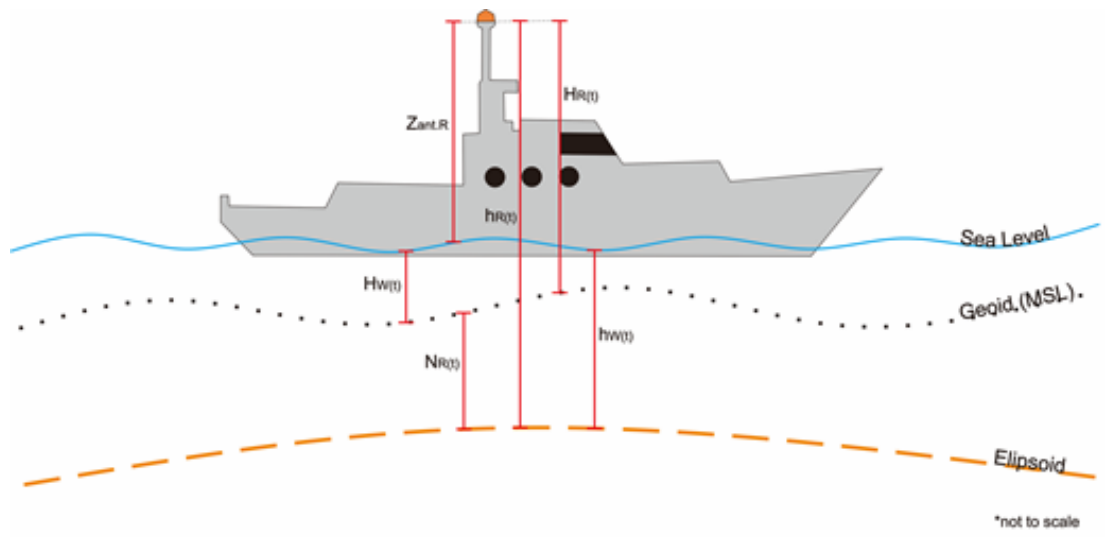

Gambar 3. Komponen Vertikal pasut GNSS (Pengarang, 2020)

Pengolahan data yang kedua adalah pengolahan data prediksi pasang surut. Data prediksi pasang surut dari BIG tidak memiliki metadata sehingga tidak diketahui referensi datum vertikal yang digunakan. Oleh karena itu, diperlukan penyamaan datum vertikal terhadap data pasut GNSS agar data yang dibandingkan saling bertampalan atau overlaping. Penyamaan datum vertikal dilakukan dengan cara mencari offset antara data pengamatan pasut GNSS dan prediksi pasut BIG. Nilai offset dapat dicari dengan menghitung selisih dari nilai MSL masing-masing data. Setelah itu, overlaping data dilakukan dengan cara mengurangi atau menambahkan nilai tinggi muka air laut dengan nilai offset yang didapat. Data output yang dihasilkan pada proses ini adalah data prediksi pasut yang sudah satu referensi dengan datum vertikal pasut GNSS yaitu MSL.

Langkah terakhir dari tahap pengolahan data ini adalah membandingkan nilai tinggi muka air laut hasil dari pengamatan GNSS yang bereferensi pada geoid (diasumsikan berhimpit dengan MSL) terhadap nilai tinggi 
muka air laut model prediksi pasang surut. Hasil perbandingan nilai tersebut nantinya dianalisis menjadi nilai Root Mean Square Error (RMSE).

\section{Hasil dan Pembahasan}

Pengolahan data pada penelitian ini diolah per hari termasuk perhitungan RMSE karena nilai data sangat bervariasi dan lokasi survei yang berbeda tiap harinya. Lokasi pengamatan berada di Laut Sulawesi hingga Selat Makassar dengan koordinat seperti pada Tabel 1. Berikut peta lokasi pengamatan dan grafik tinggi elipsoid pada tanggal 6 - 8 Agustus 2019 yang ditunjukkan pada Gambar 4. Titik-titik merah pada grafik di Gambar 4 merupakan tinggi elipsoid receiver di atas kapal. Sementara itu, titik-titik merah yang terlihat seperti garis pada peta adalah lokasi kapal yang bergerak. Faktor roll, pitch, dan heave kapal diabaikan karena kapal diasumsikan bergerak dengan keadaan tenang. Data tinggi elipsoid ini masih terdapat noise yang nantinya harus dibersihkan agar pola grafik yang dihasilkan menjadi lebih baik.

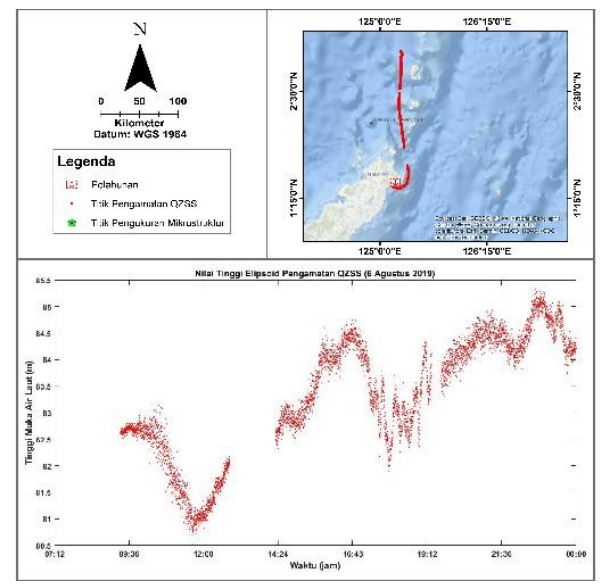

(a)

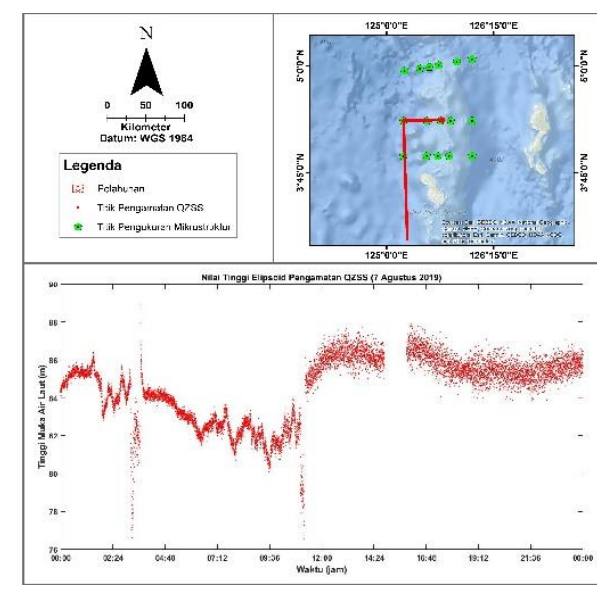

(b)

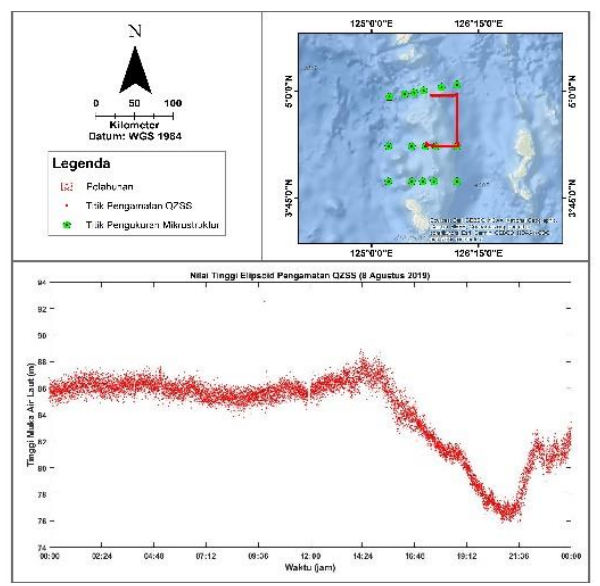

(c)

Gambar 4. Peta Lokasi Pengamatan Pasut QZSS dan Grafik Tinggi Elipsoid: (a) 6 Agustus 2019; (b) 7 Agustus 2019; dan (c) 8 Agustus 2019.

Tinggi elipsoid receiver tersebut kemudian dikoreksi dengan undulasi dan tinggi dari antena receiver ke permukaan air laut sehingga didapatkan tinggi orthometrik dari muka air laut seperti yang ditunjukkan pada Gambar 5.

Pada Gambar 5, garis berwarna kuning menunjukkan batas data noise dan garis berwarna merah merupakan data hasil local regression. Data tinggi muka air laut yang berada di luar batas atas maupun batas bawah merupakan data noise sehingga harus dilakukan clearing. Metode yang digunakan untuk melakukan clearing data noise dan smoothing tersebut adalah metode local regression dan moving average filtering. Span data 
pada proses moving average filtering dibuat sama dengan pengamatan selama satu jam yaitu sebanyak 360 data (interval data per 10 detik). Hal dilakukan agar sesuai dengan epoch dari data prediksi pasut BIG.

Gambar 6 menunjukkan grafik dari nilai tinggi muka air laut pada tanggal 6 - 8 Agustus 2019 yang sudah dilakukan clearing dan moving average filtering. Pada Gambar 6, titik-titik biru merupakan nilai tinggi muka air laut yang berada di dalam batas (bukan noise) dan garis merah merupakan hasil moving average filtering yang akan dibandingkan dengan data prediksi pasut BIG.

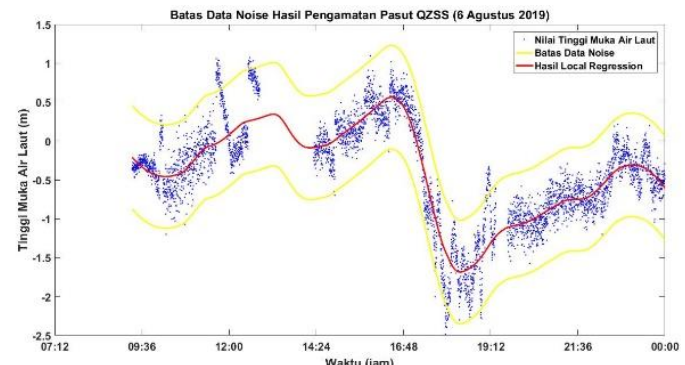

(a)

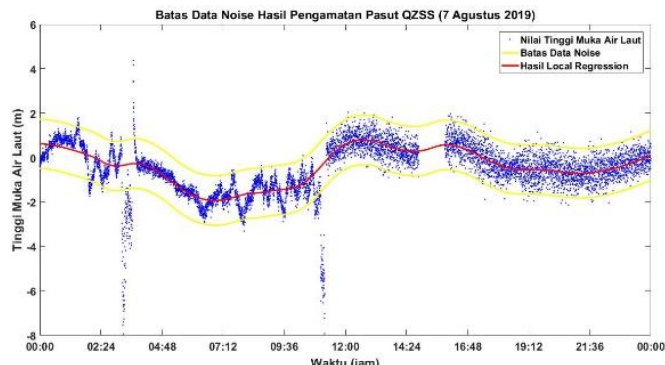

(b)

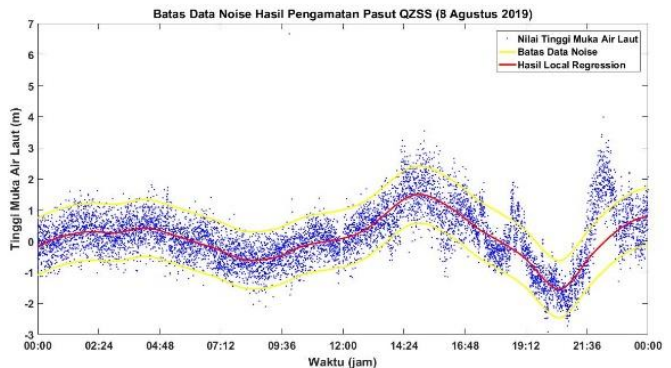

(c)

Gambar 5. Noise Pasut GNSS: (a) 6 Agustus 2019; (b) 7 Agustus 2019; dan (c) 8 Agustus 2019

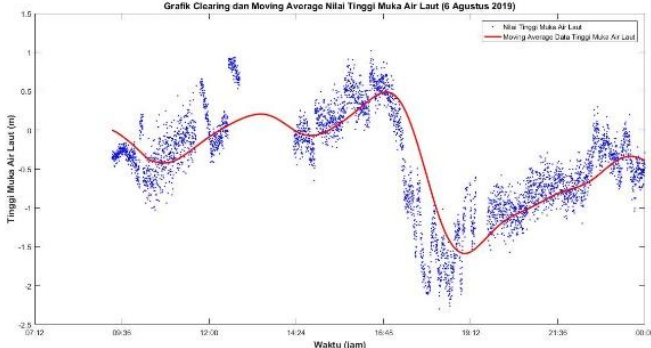

(a)

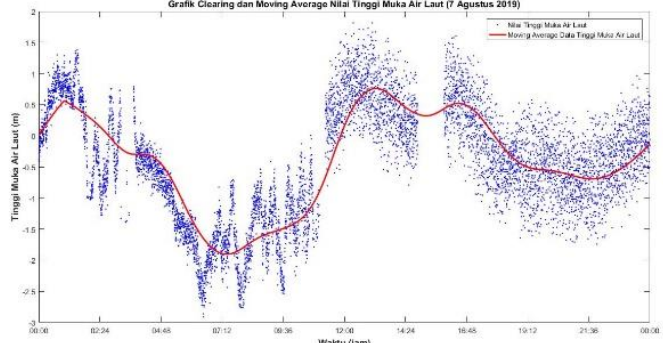

(b)

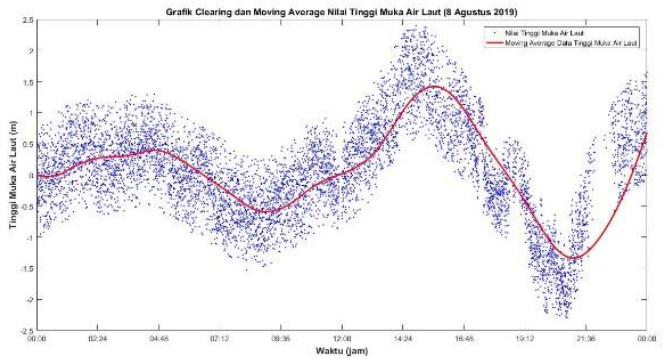

(c)

Gambar 6. Nilai Tinggi Muka Air Laut Hasil Clearing dan Moving Average Filtering: (a) 6 Agustus 2019; (b) 7 Agustus 2019; dan (c) 8 Agustus 2019

Data prediksi pasut BIG digunakan sebagai data pembanding dari pengamatan pasut QZSS. Data prediksi ini didapatkan dengan cara mengunduh dari website tides.big.go.id/pasut/ sehingga data ini termasuk data 
sekunder. Data input yang dibutuhkan yaitu berupa koordinat lintang dan bujur, serta tanggal prediksi pasut yang diinginkan. Gambar 7 menunjukkan grafik prediksi pasut per harinya pada tanggal 6- 8 Agustus 2019. Garis hitam pada Gambar 7 menunjukkan pola pasang surut dari data yang multitemporal dan multilokasi akibat kapal yang bergerak.

Perbandingan dilakukan terhadap data tinggi muka air laut hasil dari pengamatan pasut QZSS dan data prediksi pasut BIG. Dimana, nilai tinggi muka air laut hasil prediksi pasut BIG diasumsikan sebagai data yang benar karena merupakan data asimilasi dari stasiun pasut permanen dan satelit altimetri.

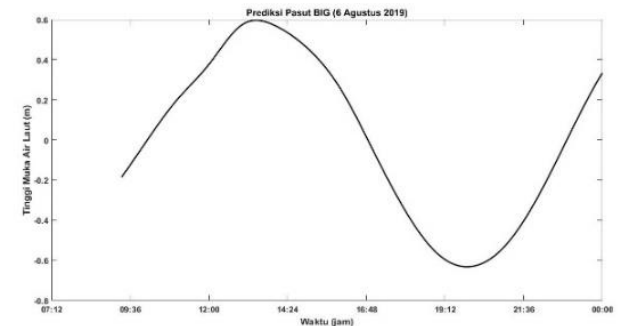

(a)

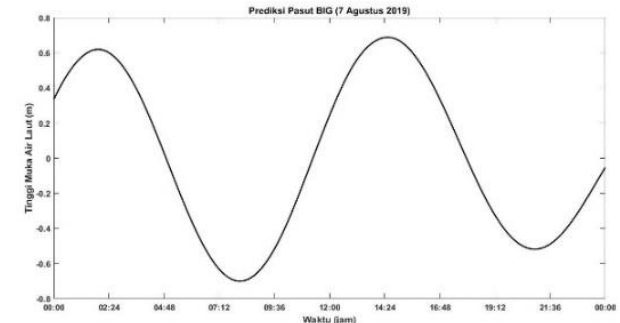

(b)

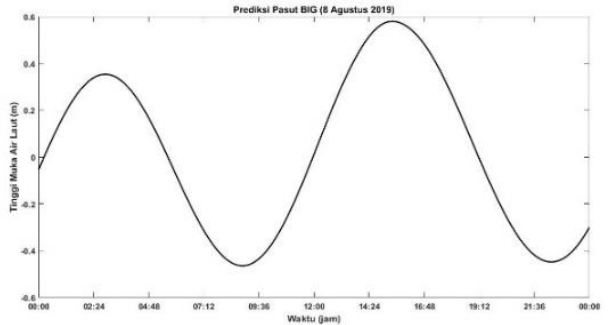

(c)

Gambar 7. Prediksi pasut BIG: (a) 6 Agustus 2019; (b) 7 Agustus 2019; dan (c) 8 Agustus 2019

Gambar 8 menunjukkan grafik perbandingan nilai tinggi muka air laut dari pengamatan pasut QZSS dan prediksi pasut BIG pada tanggal 6 - 8 Agustus 2019. Garis hitam menunjukkan grafik prediksi pasut BIG dan garis merah merupakan pasut QZSS yang telah dilakukan proses moving average filtering. Kemudian, untuk melihat residu dari perbandingan kedua data dapat dilihat pada garis hijau di Gambar 9.

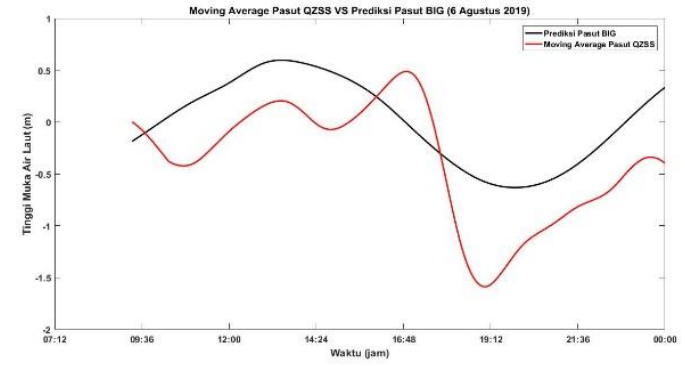

(a)

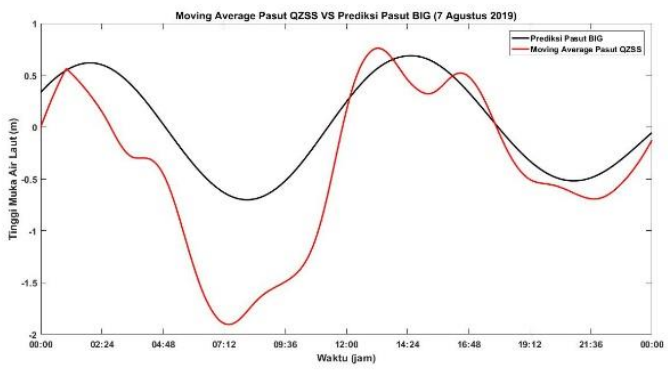

(b)

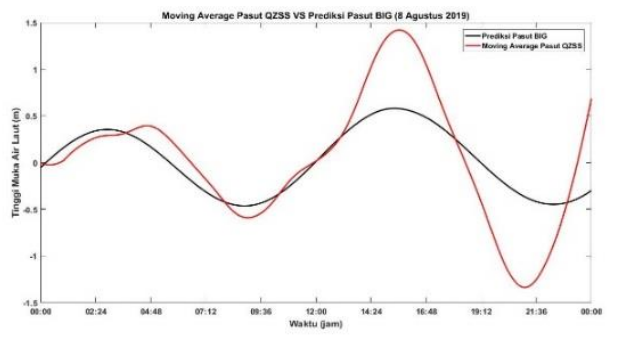

(c)

Gambar 8. Perbandingan Tinggi Muka Air Laut: (a) 6 Agustus 2019; (b) 7 Agustus 2019; dan (c) 8 Agustus 2019 
Secara keseluruhan, pola grafik nilai tinggi muka air laut dari semua pengamatan pada tanggal 6 - 16 Agustus 2019 relatif sama namun tetap memiliki selisih nilai tinggi muka air laut. Dilihat dari grafik yang dihasilkan, data pengamatan pasut QZSS dan prediksi pasut BIG sudah bertampalan atau overlapping sehingga tidak perlu mencari offset antara kedua data tersebut. Mencari offset diperlukan apabila data yang dibandingkan tidak bertampalan karena perbedaan referensi. Pada penelitian kali ini hal itu tidak perlu dilakukan karena data sudah bertampalan sehingga dapat disimpulkan pula bahwa data prediksi pasut yang dimiliki oleh BIG bereferensi pada MSL Analisis selanjutnya adalah menghitung tingkat kesalahan pada nilai tinggi muka air laut pengamatan pasut QZSS dan prediksi pasut BIG. Uji tingkat kesalahan dilakukan dengan menghitung nilai RMSE pada masing-masing waktu pengamatan (tanggal 6-16 Agustus 2019). Perhitungan RMSE dapat dilakukan dengan menggunakan rumus sebagai berikut (Ghilani dan Wolf, 2011):

$$
R M S E=\sqrt{\frac{\sum_{i=1}^{n}\left(y_{p i}-y_{o i}\right)^{2}}{n}}
$$

Dimana, $y_{o i}$ adalah nilai data pengukuran ke-i, $y_{p i}$ adalah nilai data prediksi ke-i, dan n adalah jumlah data. Dari perhitungan tersebut, didapatkan nilai RMSE seperti pada Tabel 2.

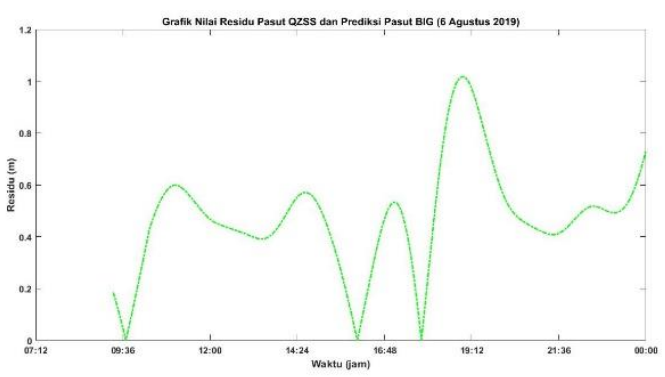

(a)

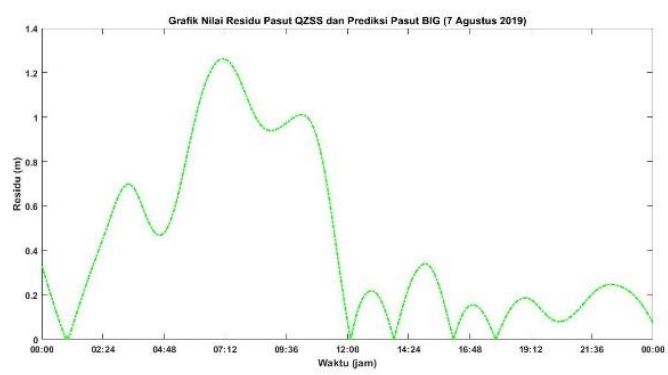

(b)

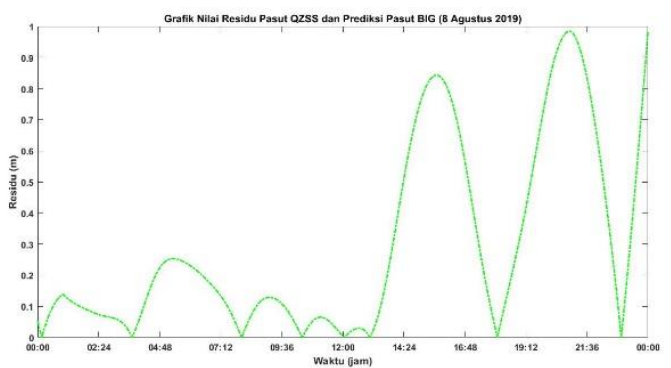

(c)

Gambar 9. Grafik Nilai Residu Perbandingan Tinggi Muka Air Laut: (a) 6 Agustus 2019; (b) 7 Agustus 2019; dan (c) 8 Agustus 2019

Tabel 2. Nilai RMSE Pasut QZSS dan Prediksi Pasut BIG

\begin{tabular}{|c|c|c|}
\hline Tanggal & Perbandingan & RMSE (m) \\
\hline $6 / 8 / 2019$ & \multirow{7}{*}{ 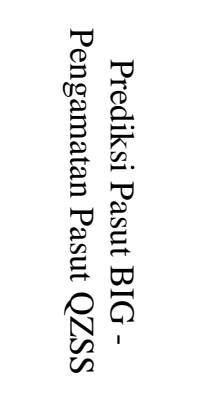 } & 0,513 \\
\hline $7 / 8 / 2019$ & & 0,573 \\
\hline 8/8/2019 & & 0,416 \\
\hline 9/8/2019 & & 0,176 \\
\hline $10 / 8 / 2019$ & & 2,317 \\
\hline $11 / 8 / 2019$ & & 0,765 \\
\hline $12 / 8 / 2019$ & & 0,373 \\
\hline
\end{tabular}




\begin{tabular}{|c|c|}
\hline $13 / 8 / 2019$ & 0,674 \\
\hline $14 / 8 / 2019$ & 0,494 \\
\hline $15 / 8 / 2019$ & 0,331 \\
\hline $16 / 8 / 2019$ & 0,426 \\
\hline
\end{tabular}

Pada perbandingan nilai tinggi muka air laut hasil pengamatan pasut QZSS dan prediksi pasut BIG, nilai RMSE terbesar adalah pada tanggal 10 Agustus 2019 dengan nilai 2,317 meter. Sedangkan, RMSE terkecil terjadi pada pengamatan QZSS tanggal 9 Agustus 2019 dengan nilai 0,176 meter. Perbedaan yang dihasilkan antara tinggi muka air laut hasil pengamatan pasut QZSS dan prediksi pasut BIG tidak selalu menghasilkan ketelitian pada level sentimeter $(\mathrm{cm})$, yang terjadi pada penelitian ini bahkan sampai pada level meter $(\mathrm{m})$. Hal tersebut dapat terjadi karena beberapa faktor seperti kesalahan pada pengukuran tinggi stasiun base, kesalahan pada pengukuran tinggi antena rover, dan kesalahan pada model separasi (Dodd dan Mills, 2014).

Dari hasil plotting koordinat pengamatan QZSS dan catatan survei, dapat dianalisis beberapa faktor yang mempengaruhi nilai RMSE antara pasut QZSS dan prediksi pasut BIG. RMSE akan menghasilkan nilai yang besar jika kapal bergerak atau bermanuver tinggi dan menghasilkan nilai yang kecil jika sedang berhenti. Perlu diketahui bahwa data yang digunakan pada penelitian ini berasal dari receiver yang dipasang di kapal yang sedang melakukan pengukuran mikrostruktur sehingga kapal akan berhenti/memperlambat manuvernya untuk melakukan pengukuran.

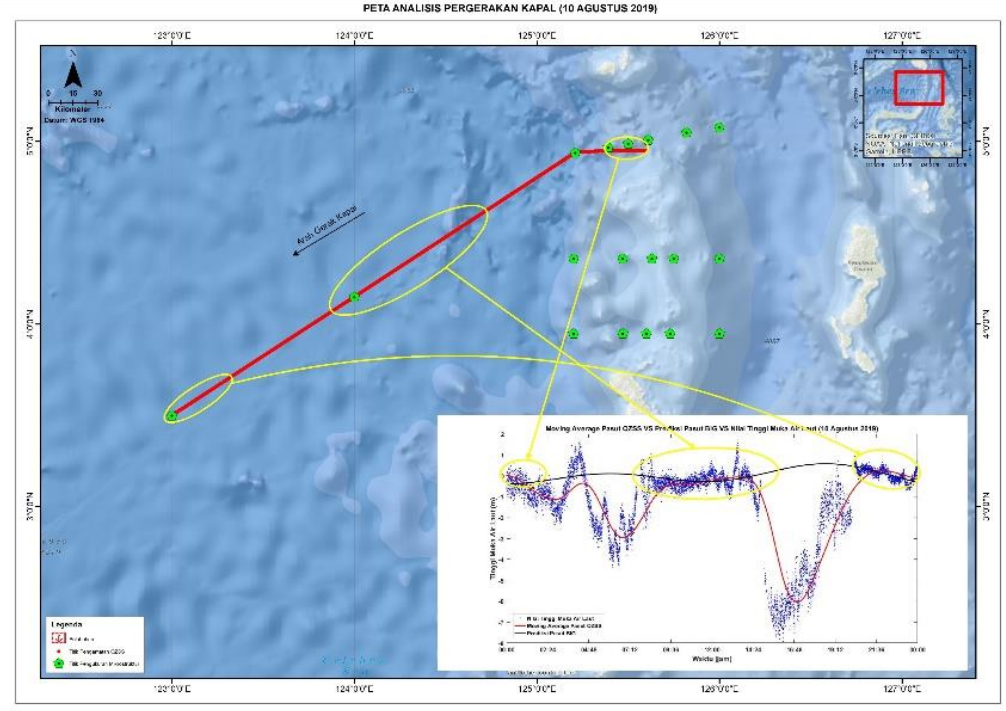

Gambar 10. Peta Analisis Pergerakan Kapal pada 10 Agustus 2019

Pada Gambar 10 ditampilkan plotting koordinat dan kondisi tinggi muka air laut pada tanggal 10 Agustus 2019 yang merupakan data dengan nilai RMSE tertinggi. Titik merah yang terlihat seperti garis merah pada peta adalah plotting dari lokasi kapal yang bergerak. Sementara itu, garis merah pada grafik merupakan hasil moving average pasut QZSS dan garis hitam adalah prediksi pasut BIG. Pada grafik tersebut juga terdapat titik biru yang merupakan nilai tinggi muka air laut yang bereferensi pada geoid. Dapat dilihat bahwa tinggi muka air laut pengamatan QZSS pada jam-jam tertentu sangat berbeda sekali dengan prediksi BIG. Ini dapat disebabkan karena dinamika kapal yang begitu besar ketika bermanuver ditambah lagi kondisi cuaca yang buruk. Menurut catatan survei, diketahui bahwa pada saat survei dilakukan gelombang laut cukup besar akibat pengaruh Topan Lekima dari Samudera Pasifik yang mengarah ke Filipina, Taiwan, dan Jepang. Cuaca buruk tersebut mengakibatkan gelombang laut yang terjadi berkisar antara 1-2,5 meter. Gelombang laut sebesar itu terjadi sejak tanggal 6 Agustus 2019 - 13 Agustus 2019 ketika kapal melewati Laut Sulawesi dan Utara Selat Makassar. Namun, data tanggal 10 Agustus 2019, pada jam-jam tertentu, juga memberikan hasil yang baik. Dapat dilihat garis dan lingkaran kuning pada Gambar 10 menunjukkan lokasi dan kondisi tinggi muka air laut 
yang bertampalan. Hasil yang baik ini dapat disebabkan karena kapal sedang atau akan melakukan pengukuran mikrostruktur sehingga manuver kapal diperlambat sehingga dinamika pergerakan kapal tidak terlalu besar.

Analisis yang menguatkan adanya pengaruh dinamika kapal dapat dilihat pada Gambar 11 yaitu plotting koordinat dan kondisi tinggi muka air laut pada tanggal 9 Agustus 2019 yang merupakan data dengan nilai RMSE terkecil. Keterangan Gambar 11 sama seperti Gambar 10 dimana garis dan lingkaran kuning menunjukkan lokasi dan kondisi tinggi muka air laut yang bertampalan. Grafik yang saling bertampalan tersebut disebabkan karena kapal sedang berhenti untuk melakukan pengukuran mikrostruktur yaitu pada jam 04.40 sampai 23:59 (dalam UTC). Oleh karena kapal tidak melakukan perjalanan, dinamika kapal yang terjadi tidak terlalu besar sehingga dapat menggambarkan kondisi muka air laut yang sebenarnya. Sementara itu, dapat dilihat data tinggi muka air laut di luar lingkaran kuning menunjukkan grafik yang tidak terlalu teratur. Hal itu disebabkan karena kapal sedang bergerak menuju titik pengukuran mikrostruktur.

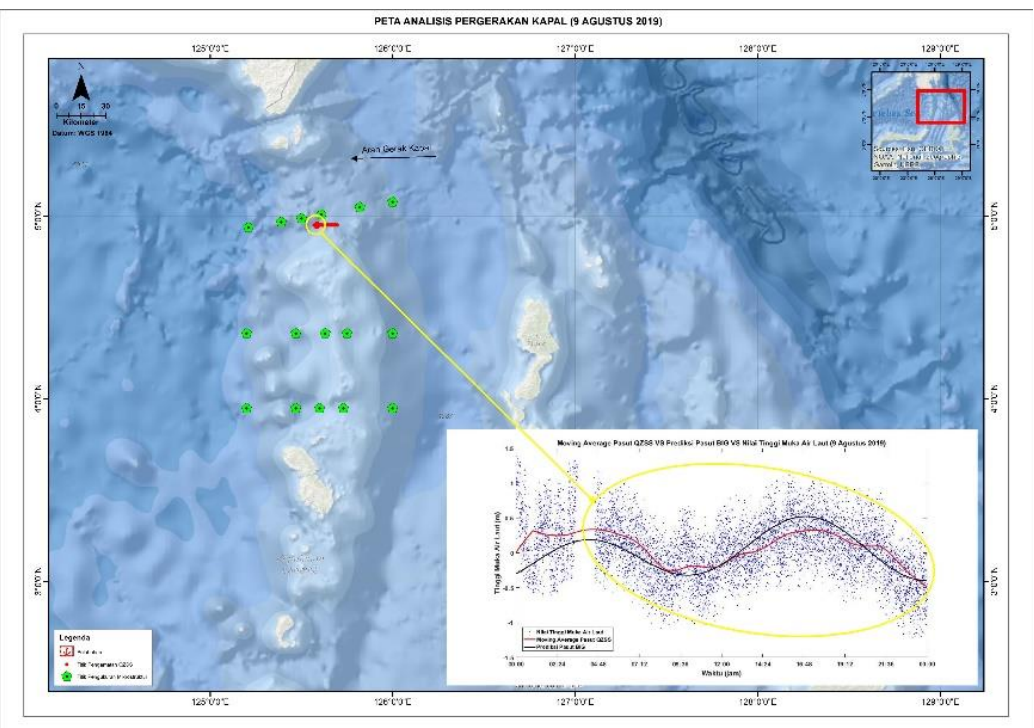

Gambar 11. Peta Analisis Pergerakan Kapal pada 9 Agustus 2019

Analisis di atas membuktikan bahwa dinamika kapal berperan besar pada ketelitian pola yang dihasilkan antara pasut QZSS dan prediksi BIG. Sehubungan dengan itu, faktor-faktor gerak kapal seperti pitch, roll, dan heave kapal sejatinya harus dipertimbangkan agar semua data dapat memberikan grafik yang baik karena dikoreksi dengan dinamika gerakan kapal. Sebagai tambahan, nilai RMSE yang didapat dari penelitian ini bukan menunjukkan tingkat kesalahan dari pengamatan QZSS, tetapi kesalahan pola yang dihasilkan. Data pengamatan QZSS ini sendiri telah dikoreksi dengan metode precise point positioning (PPP) sehingga dapat menghasilkan ketelitian sampai 10 sentimeter (Marreiros, 2012).

\section{Kesimpulan}

Pada penelitian Analisis Tinggi Muka Air Laut Menggunakan Receiver Multi-Frekuensi dan Multi-GNSS Di Perairan Sulawesi yang telah dilakukan, dapat diambil kesimpulan bahwa pada dasarnya pola pasut pengamatan QZSS relatif sama dengan pola pasut prediksi BIG, walaupun terdapat perbedaan yang cukup besar pada beberapa waktu. Sementara itu, selama 11 hari pengamatan, pola yang paling mirip terjadi pada tanggal 9 Agustus 2019 jam 04:40 sampai 23:59 (dalam UTC) karena kapal berhenti untuk melakukan pengukuran mikrostruktur. Nilai RMSE terkecil dan terbesar yang didapat masing-masing sebesar 0,176 meter pada tanggal 9 Agustus 2019 dan 2,317 meter pada tanggal 10 Agustus 2019. Dari analisis pergerakan kapal diketahui bahwa dinamika pergerakan kapal sangat mempengaruhi nilai RMSE perbandingan grafik muka air laut yang didapat. Selain itu, dari proses overlapping data diketahui bahwa data prediksi pasut yang dimiliki oleh BIG bereferensi pada MSL. Hal tersebut dibuktikan dengan langsung bertampalnya data prediksi pasut 
BIG terhadap nilai tinggi muka air laut hasil pengamatan QZSS yang sudah direduksi dengan undulasi (bereferensi pada MSL).

\section{Ucapan Terimakasih}

Penulis mengucapkan terima kasih kepada perusahaan Magellan Systems Japan sebagai pihak penyedia data pengamatan GNSS, kepada BIG sebagai pihak penyedia data prediksi pasang surut, dan kepada Balai Teknologi Survei Kelautan-BPPT beserta personil survei dan kru kapal Baruna Jaya IV sebagai pihak pelaksana survei. Oleh karena pihak-pihak tersebut, penelitian ini dapat terlaksana.

\section{Daftar Pustaka}

Dodd, D., dan Griffin, J. (2010). Application of GPS Heights to Bay of Fundy Multibeam Data. Lighthouse.

Dodd, D., dan Mills, J. (2014). Ellipsoidally Referenced Surveying for Hydrography. International Federation of Surveyor (FIG).

Ghilani, C. D., dan Wolf, P. R. (2011). Adjustment Computations: Spatial Data Analysis. International Journal of Geographical Information Science Vol.25 Ed 4. Hoboken, New Jersey: John wiley and Sons, Inc.

Abidin, H. Z. (2007). Penentuan Posisi dengan GPS dan Aplikasinya Ed 3. Jakarta: PT. Pradnya Paramita.

Marreiros, J. P. (2012). Kinematic GNSS Precise Point Positioning Application to Marine Platforms. Porto: University of Porto.

R. H. Stewart. (2008). Introduction to Phycical Oceanography. American Journal of Physics, Vol.65.

S. Haryono dan Narni. (2004). Karakteristik Pasang Surut di Pulau Jawa. Jurnal Forum Teknik, Vol.28. hal. 1-5. 